\title{
Improvement of Surface Properties of Inconel718 by HVOF Coating with WC-Metal Powder and by Laser Heat Treatment of the Coating
}

\author{
Hui Gon Chun,' Tong Yul Cho, ${ }^{2}$ Jae Hong Yoon, ${ }^{3}$ and Gun Hwan Lee ${ }^{4}$ \\ ${ }^{1}$ School of Materials Science and Engineering, University of Ulsan, Ulsan 680-749, Republic of Korea \\ ${ }^{2}$ Institute of Industrial Technology, Changwon National University, Changwon 641-773, Republic of Korea \\ ${ }^{3}$ School of Nano Advanced Materials Engineering, Changwon National University, Changwon 641-773, Republic of Korea \\ ${ }^{4}$ Surface Technology Department, Korea Institute of Material Science, Changwon 642-010, Republic of Korea
}

Correspondence should be addressed to Hui Gon Chun; chunhuigon@gmail.com

Received 22 September 2014; Accepted 9 December 2014

Academic Editor: Kwangho Kim

Copyright (C) 2015 Hui Gon Chun et al. This is an open access article distributed under the Creative Commons Attribution License, which permits unrestricted use, distribution, and reproduction in any medium, provided the original work is properly cited.

\begin{abstract}
High-velocity oxygen-fuel (HVOF) thermal spray coating with WC-metal powder was carried out by using optimal coating process on an Inconel718 surface for improvement of the surface properties, friction, wear, and corrosion resistance. Binder metals such as $\mathrm{Cr}$ and $\mathrm{Ni}$ were completely melted and $\mathrm{WC}$ was decomposed partially to $\mathrm{W}_{2} \mathrm{C}$ and graphite during the high temperature (up to $3500^{\circ} \mathrm{C}$ ) thermal spraying. The melted metals were bonded with WC and other carbides and were formed as WC-metal coating. The graphite and excessively sprayed oxygen formed carbon oxide gases, and these gases formed porous coating by evolution of the gases. The surface properties were improved by HVOF coating and were improved further by $\mathrm{CO}_{2}$ laser heat treatment (LH). Wear resistance of In718 surface was improved by coating and $\mathrm{LH}$ at $25^{\circ} \mathrm{C}$ and an elevated temperature of $450^{\circ} \mathrm{C}$, resulting in reduction of wear trace traces, and was further improved by LH of the coating in reducing wear depth. Corrosion resistance due to coating in sea water was improved by LH. HVOF coating of WC-metal powder on a metal surface and a LH of the coating were highly recommended for the improvement of In718 surface properties, the friction behavior, and wear resistance.
\end{abstract}

\section{Introduction}

Traditionally, electrolytic hard chrome plating (EHC) has been widely used for hard surface coating for over 60 years [1-3]. Recently, EHC has raised health and environmental problems; $\mathrm{Cr}^{+3}$ known as carcinogen is emitted and is forbidden in many developed countries. High-velocity oxygen-fuel (HVOF) thermal spray coating has been investigated as one of the most promising candidates for the replacement of EHC [4-6]. HVOF coatings of WC cermets have been widely used to protect machine components from wear and corrosion, to restore worn components, and to improve the durability of components.

In this work, micron-sized WC-metal powders were coated on In718 (substrate) by HVOF thermal spraying to improve the surface properties, wear resistance, and the durability of the metal components. For further improvement, the surface was irradiated with a $\mathrm{CO}_{2}$ laser $(10.6 \mu \mathrm{m}$, continuous mode, $400 \mathrm{~W})$ on an oval-shaped focal spot $(5 \mathrm{~mm} \times 4 \mathrm{~mm})$ for $0.6 \mathrm{~s}$ at the scanning speed of $400 \mathrm{~mm} / \mathrm{min}$, heating from $950^{\circ} \mathrm{C}$ to $1200^{\circ} \mathrm{C}$ from the edge to the center of the spot without heating the whole substrate not to change any structure and properties of substrate. In this experiment, the following were investigated; optimal coating process (OCP) using Taguchi experimental program, laser heat treatment (LH), changes of phases, micro-structures, surface properties, friction, wear and corrosion of HVOF coating and LH coating.

\section{Experiment}

2.1. Preparation of Coating. The chemical composition of WC-metal powder (hard cermet WC, bonding metals as $\mathrm{Ni}$ and $\mathrm{Cr}$ ) was coated on the super alloy In718 substrate in Table 1 by using JK3500 HVOF thermal spraying equipment. 
TABLE 1: Major chemical compositions of In718 and WC-metal powder.

\begin{tabular}{lcccccccc}
\hline Elements & $\mathrm{W}$ & $\mathrm{C}$ & $\mathrm{Cr}$ & $\mathrm{Ni}$ & $\mathrm{Fe}$ & $\mathrm{Nb}$ & $\mathrm{Mo}$ & Others \\
\hline In718 & & 0.08 & $17-20$ & $50-55$ & $11-22$ & $5-6$ & $2-3$ & $\mathrm{Mn}, \mathrm{Ti}, \mathrm{Si}$ \\
\hline WC-metal & 68 & 5 & 21 & 6 & & & & \\
\hline
\end{tabular}

TABLE 2: Coating processes prepared by Taguchi program and OCP of the highest surface hardness.

\begin{tabular}{lccccc}
\hline Process & $\begin{array}{c}\text { Oxygen } \\
\text { FR }\end{array}$ & $\begin{array}{c}\text { Hydrogen } \\
\text { FR }\end{array}$ & $\begin{array}{c}\text { Feed } \\
\text { rate }\end{array}$ & $\begin{array}{c}\text { Spray } \\
\text { distance (in) }\end{array}$ & $\begin{array}{c}\text { Hardness } \\
(\mathrm{Hv})\end{array}$ \\
\hline 1 & 30 & 53 & 25 & 6 & 973 \\
2 & 30 & 57 & 30 & 7 & 943 \\
3 & 30 & 61 & 35 & 8 & 913 \\
4 & 34 & 53 & 35 & 7 & 976 \\
5 & 34 & 57 & 25 & 8 & 942 \\
6 & 34 & 61 & 30 & 6 & 930 \\
7 & 38 & 53 & 30 & 8 & 1033 \\
8 & 38 & 57 & 35 & 6 & 960 \\
9 & 38 & 61 & 25 & 7 & 998 \\
OCP & $\mathbf{3 8}$ & $\mathbf{5 3}$ & $\mathbf{2 5}$ & $\mathbf{7}$ & $\mathbf{1 1 5 0}$ \\
\hline
\end{tabular}

FR: flow rate $\left(\mathrm{FMR}=12 \mathrm{scfh}=9.44 \times 10^{-5} \mathrm{~m}^{3} / \mathrm{s}\right)$, feed rate: $\mathrm{g} / \mathrm{min}$, and OCP: optimal coating process.

The substrates were pre-cleaned in acetone for 5 minutes and then blast cleaned using 60-mesh aluminum oxides to improve adhesion onto In718 substrate. As shown in Table 2, OCP was obtained among the best surface properties of the 9 coatings prepared Taguchi experimental program for 3 levels of 4 spray parameters. Hydrogen flow rate as value was 53 FMR $\left(F M R=12 \mathrm{scfh}=9.44 \times 10^{-5} \mathrm{~m}^{3} / \mathrm{s}\right)$, oxygen flow rate as $38 \mathrm{FMR}$, powder feed rate as $25 \mathrm{~g} / \mathrm{min}$, and spray distance as $18 \mathrm{~cm}$. Argon gas of 120-180 psi was used as a powder carrier gas at feed rate of $25-35 \mathrm{~g} / \mathrm{min}$. The preparation of coatings was provided by OCP and heat-treated by $\mathrm{CO}_{2}$ laser.

\subsection{Preparation of LH Coating. A 5-kW TJ-HL-T 5000-} type equipment was used for $\mathrm{CO}_{2}$ laser heat treatment. The laser beam $(10.6 \mu \mathrm{m}$, continuous mode, a top-hat laser beam energy distribution in the focal spot) irradiated the substrate from the spot $18.5 \mathrm{~mm}$ above in an atmospheric environment. The laser beam with a focal spot of $5 \mathrm{~mm} \times 4 \mathrm{~mm}$ (oval shape) moved along the beam direction of the $4 \mathrm{~mm}$ at velocity of $400 \mathrm{~mm} / \mathrm{min}$, resulting in a $\mathrm{LH}$ time of $0.6 \mathrm{~s}$ on the spot. Argon gas (10 MPa pressure and $5 \mathrm{~L} / \mathrm{min}$ flow rate) was used for shrouding the $\mathrm{LH}$ region to prevent oxidation during the process.

The laser power was turned off for $5 \mathrm{~s}$ at the end of each pass for a new starting position. The laser beam tracks were overlapped by $40 \%$ to each other. The optimal laser LH parameters were laser power of $400 \mathrm{~W}$, scanning speed of $400 \mathrm{~mm} / \mathrm{min}$, average power density of $20 \mathrm{~W} / \mathrm{mm}^{2}$, and laser irradiation of $0.6 \mathrm{~s}$ on spot. The samples were heattreated in a furnace at $150^{\circ} \mathrm{C}$ for 2 hours before and after laser heat treatments. The temperature from edge to center of the laser spot was in the range from $950^{\circ} \mathrm{C}$ to $1200^{\circ} \mathrm{C}$ using a multiwavelength pyrometer.

2.3. Investigation of Surface Properties, Friction, Wear, and Corrosion in HVOF Coating and LH Coating. The microstructures of HVOF coating and the LH coating were investigated by using scanning electron microscope (SEM). The phase changes by HVOF powder coating and LH coating were investigated using X-ray diffraction (XRD). Surface hardness was measured by using a Micro Vickers hardness tester with a load of $200 \mathrm{~g}$ and a dwelling time of $10 \mathrm{~s}$. Porosity was measured by analyzing the images of optical microscope.

Friction and the wear behaviors were investigated by using a reciprocating slide tester (TE77 AUTO, Plint \& Partners). The surfaces were slid by using SUS 304 balls (diameter $9.53 \mathrm{~mm}$ and hardness $227 \mathrm{Hv}$ ) without lubricants. Before the test, the surfaces were polished to $\mathrm{Ra} 1-1.4 \mu \mathrm{m}$ by using silicon carbide abrasive paper and DP-paste. The sliding distance, frequency, speed, load, and sliding time were $16 \mathrm{~mm}$, $2.5 \mathrm{~Hz}, 0.161 \mathrm{~m} / \mathrm{s}, 10 \mathrm{~N}$, and $10 \mathrm{~min}$, respectively. Sliding wear tests were carried out for the substrate, HVOF coating, and LH coating to study the friction and wear behaviors. Wear traces were investigated using SEM and EDS. The depth profiles of the wear traces were investigated using a surface profiler (Tencor P-11).

The corrosion behavior of HVOF coating and $\mathrm{LH}$ coating was investigated in sea water ( $3.5 \mathrm{wt} \% \mathrm{NaCl}$ solution).

The sample was mounted in the electrochemical cell with an exposing area of $1.0 \mathrm{~cm}^{2}$ to the electrolyte. In the electrochemical test, saturated calomel electrode (SCE) and graphite were used as the reference and counter electrode, respectively.

The electrochemical tests included the open-circuit potential (EOC) measurements and potentiodynamic polarization tests. The EOC was measured after $30 \mathrm{~min}$ immersion of the coating surface in $3.5 \mathrm{wt} \% \mathrm{NaCl}$ solution for potential stabilization. The samples were potentiodynamically polarized (anodically) and the tests were performed at a scanning rate of $0.5 \mathrm{mV} / \mathrm{s}$. At least, two sets of measurements were made per sample to ensure reproducibility of the results.

\section{Results and Discussion}

3.1. HVOF Coating and LH Coating. Inhomogeneous WC pieces were imbedded in binder metals such as $\mathrm{Ni}, \mathrm{Cr}, \mathrm{Ni}-\mathrm{Cr}$ alloy, and WC powders $[3,6,7]$. During the flight of $0.02 \mathrm{~s}$ in the HVOF spraying, its velocity and temperature of the flame were reached up to $1000 \mathrm{~m} / \mathrm{s}$ and $3500^{\circ} \mathrm{C}$. The binder metals and some metal carbide were melted, and the metal carbides were decomposed into metals and free carbon. Small portion of WC was found in forms of crystalline compounds 


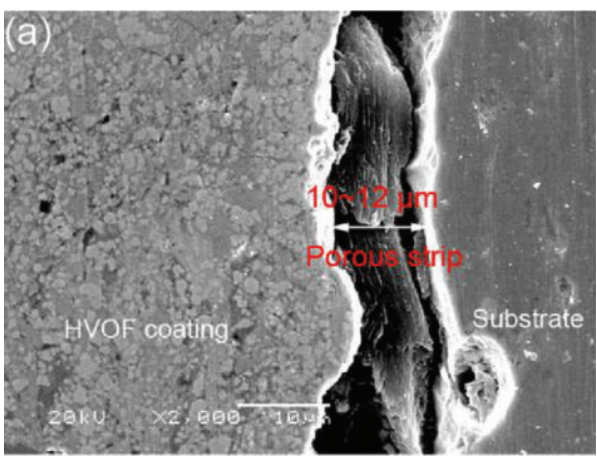

(a)

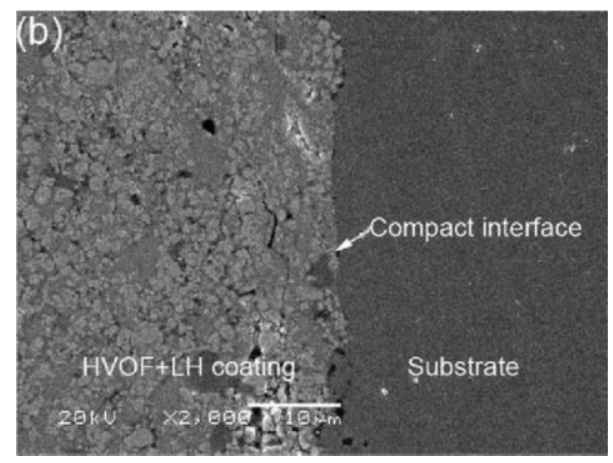

(b)

Figure 1: (a) Porous coating and interface between coating and substrate; (b) interface compacted by laser heating.

TABLE 3: Improvement of surface properties by coating and LH coating.

\begin{tabular}{lccc}
\hline Surface & In718 & Coating & LH coating \\
\hline Surface hardness (Hv) & $400 \pm 10$ & $980 \pm 100$ & $1430 \pm 90$ \\
Porosity (\%) & 0.00 & $2.5 \pm 0.5$ & $0.35 \pm 0.05$ \\
Friction coefficient & $0.45 \pm 0.08$ & $0.32 \pm 0.02$ & $0.20 \pm 0.03$ \\
\hline
\end{tabular}

such as $\mathrm{W}_{2} \mathrm{C}[7,8]$. The melts or partially molten splats were impacted on the In718 surface, forming bonds with the surface and subsequently building the porous coating as seen in Figure 1. Although the powder consisted of crystalline carbides such as WC, $\mathrm{Cr}_{7} \mathrm{C}_{3}$, and metastable $\mathrm{Ni}_{3} \mathrm{C}$, the coating showed that only crystalline WC and a new phase $\mathrm{W}_{2} \mathrm{C}$ were observed in Figure 2.

However, the other forms of crystalline carbides disappeared due to the decomposition during heating and rapid cooling processes. According to the phase diagram, $\mathrm{WC}$ is decomposed to $\mathrm{W}_{2} \mathrm{C}$ and free carbon above its decomposition temperature of $1250^{\circ} \mathrm{C}[9,10]$. The free carbon and excessively sprayed reagent oxygen formed carbon oxide gases, producing pores and voids inside the porous coating as shown in Table 3 and Figure 1.

During laser heat treatment of the HVOF coating for $0.6 \mathrm{~s}$, the temperature of the irradiated focal area was in the range from $950^{\circ} \mathrm{C}$ to $1200^{\circ} \mathrm{C}$; the porous coating and porous strips at the interface were compacted as seen in Figure 1 and Table 3. The crystalline metal carbides such as $\mathrm{Ni}_{3} \mathrm{C}$ and $\mathrm{Cr}_{3} \mathrm{C}_{2}$ phases were formed due to the longer heating time $(\sim 0.6 \mathrm{~s})$ and proper heating temperature $\left(950^{\circ} \mathrm{C}\right.$ to $\left.1200^{\circ} \mathrm{C}\right)$. This can be compared with spray coating time of about $0.02 \mathrm{~s}$ and temperature of up to $3500^{\circ} \mathrm{C}$.

3.2. Improvement of Surface Properties by HVOF Coating and LH Coating. As seen in Table 3 and Figure 3, the surface hardness and friction coefficient were improved by HVOF coating and LH coating for $0.6 \mathrm{~s}$. These properties of HVOF coating and LH coating were better than the traditional electrolytic hard chrome plating (EHC) as seen in Table 3 according to Fang et al.'s report [6]. The friction coefficient of the coating showed lower value than that of EHC

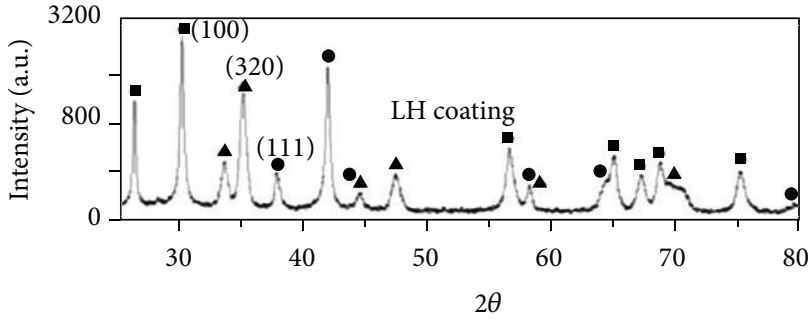

- $\mathrm{WC}$

$\Delta \mathrm{Cr}_{3} \mathrm{C}_{2}$

- $\mathrm{Ni}_{3} \mathrm{C}$

(a)

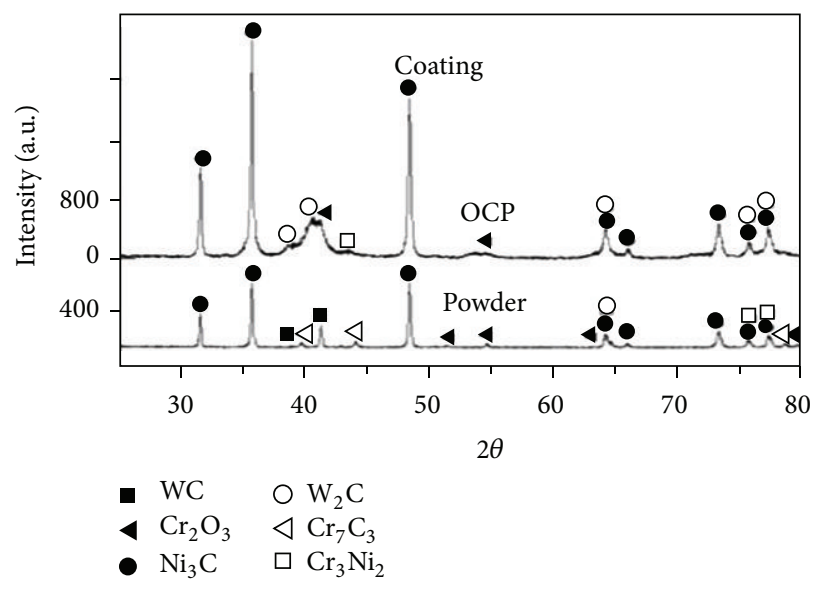

(b)

FIGURE 2: Crystalline phases of powder, coating, and LH coating.

$(0.52 \pm 0.07 \mathrm{Hv})$, and surface hardness of HVOF coating showed higher value than that of EHC $(950 \pm 50 \mathrm{Hv})$. The porous coating was formed by HVOF coating due to formation of carbon oxide gases by the reaction of free carbon (produced by the thermal decompositions of WC and metal carbides) with excessively sprayed oxygen as shown in Table 2. With laser heating, the porosity decreased drastically and HVOF coating was compacted as seen in Table 3 and Figure 1. 


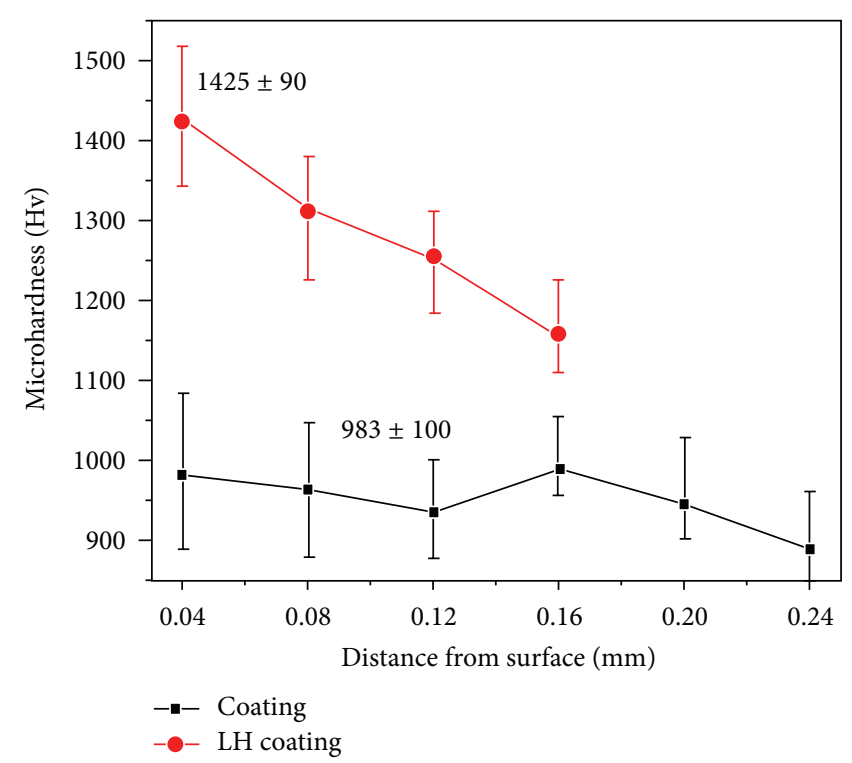

Figure 3: Depth profiles of surface hardness of coating and LH coating.
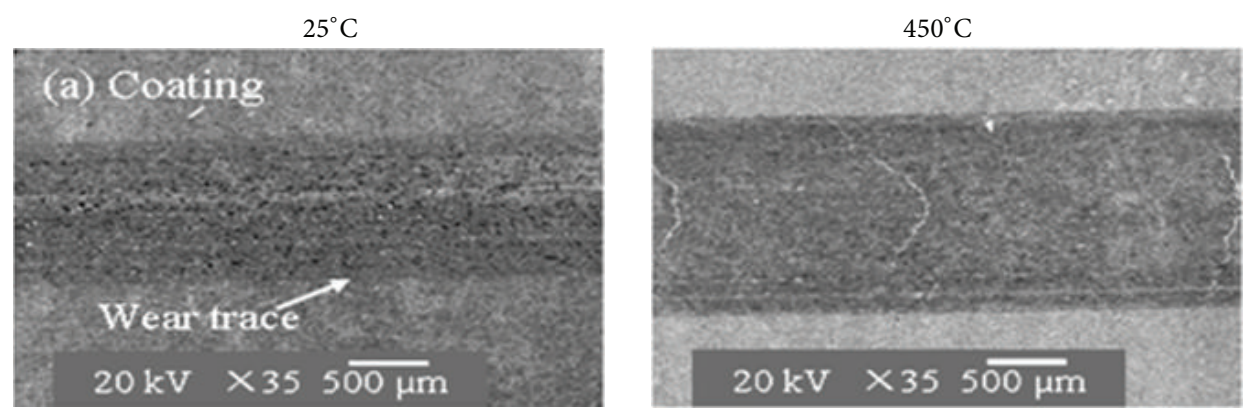

(a)
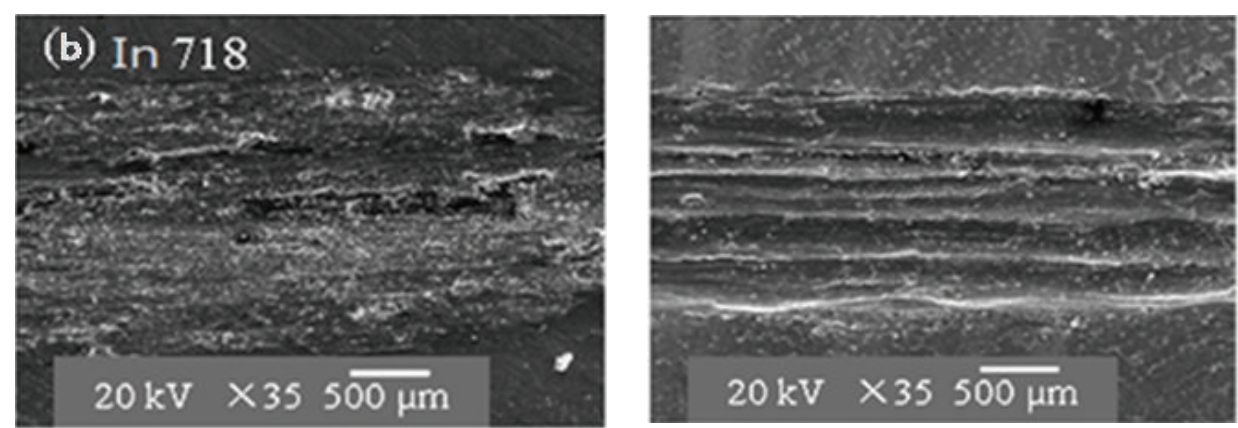

(b)

Figure 4: Wear traces of (a) coating and (b) In718 at both $25^{\circ} \mathrm{C}$ and $450^{\circ} \mathrm{C}$.

The surface hardness of In718 (400 $\pm 10 \mathrm{Hv})$ increased more than twice to $980 \pm 100 \mathrm{Hv}$ due the coating; it was increased $46 \%$ to $1430 \pm 90 \mathrm{Hv}$ by laser heating for $0.6 \mathrm{~s}$. The porosity of In718 surface ( $0 \%$ ) was increased to $2.5 \pm 0.5 \%$ by HVOF coating due to formation of carbon oxide gases inside the coating; it was reduced to $0.35 \pm 0.05 \%$ (to $14 \%$ ) by laser heating. As seen in Figure 1, laser heating could reduce their porosity by compacting of the coating and the interface of coating/substrate In718. The friction coefficient of In718 was reduced by $30 \%$ from $0.45 \pm 0.08$ to $0.32 \pm 0.02$ by coating and $10 \%$ to $0.20 \pm 0.03$ by laser heating. One of the reasons could be the lubrication by the free carbon formed by the decomposition of WC and metal carbides during the spraying and the metal-oxide debris worn during sliding test.

3.3. Improvement of Surface Wear Resistance by HVOF Coating and by $\mathrm{LH}$ Coating. A reciprocating slide test was carried out for the investigation of wear resistance and 


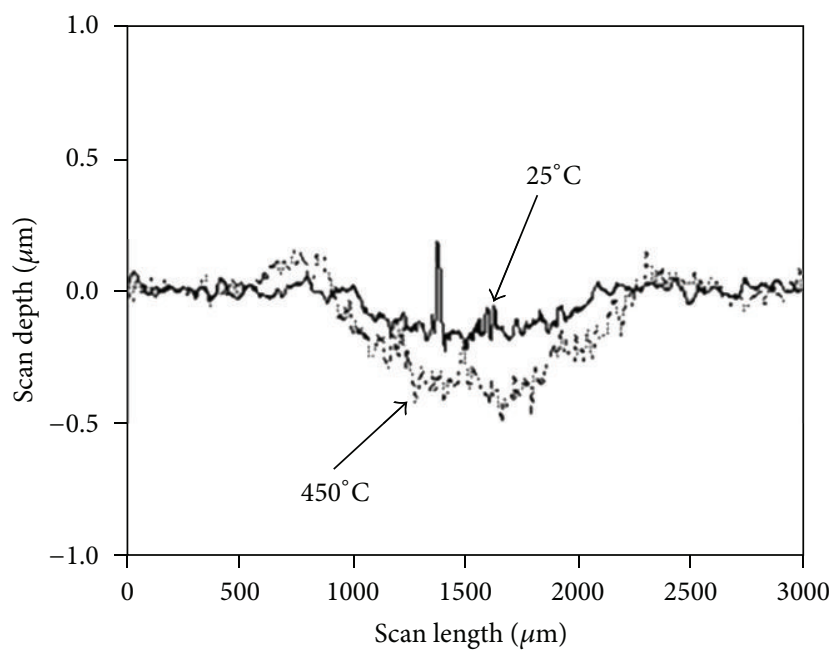

(a)

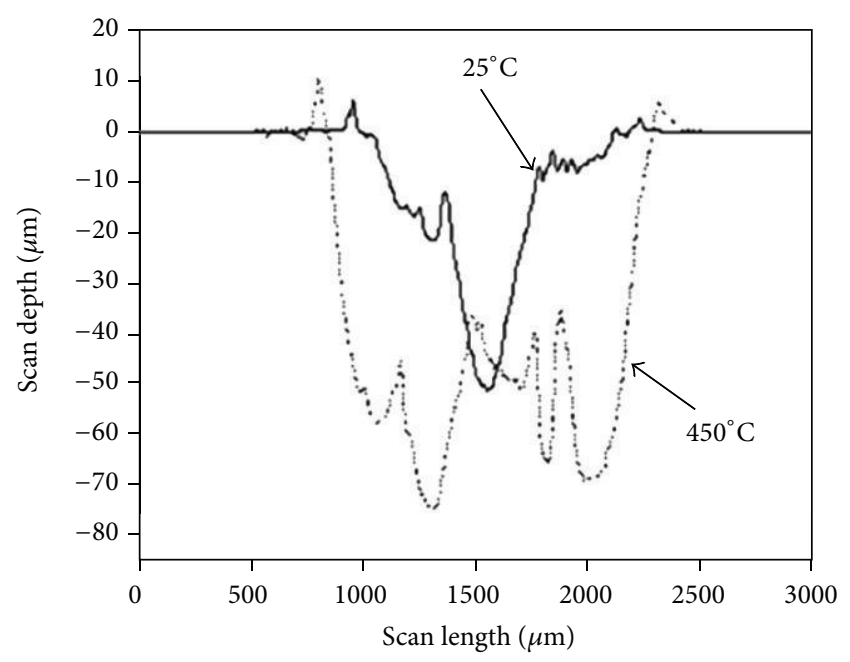

(b)

Figure 5: Wear depth profiles; (a) coating and (b) In718 at both $25^{\circ} \mathrm{C}$ and $450^{\circ} \mathrm{C}$.

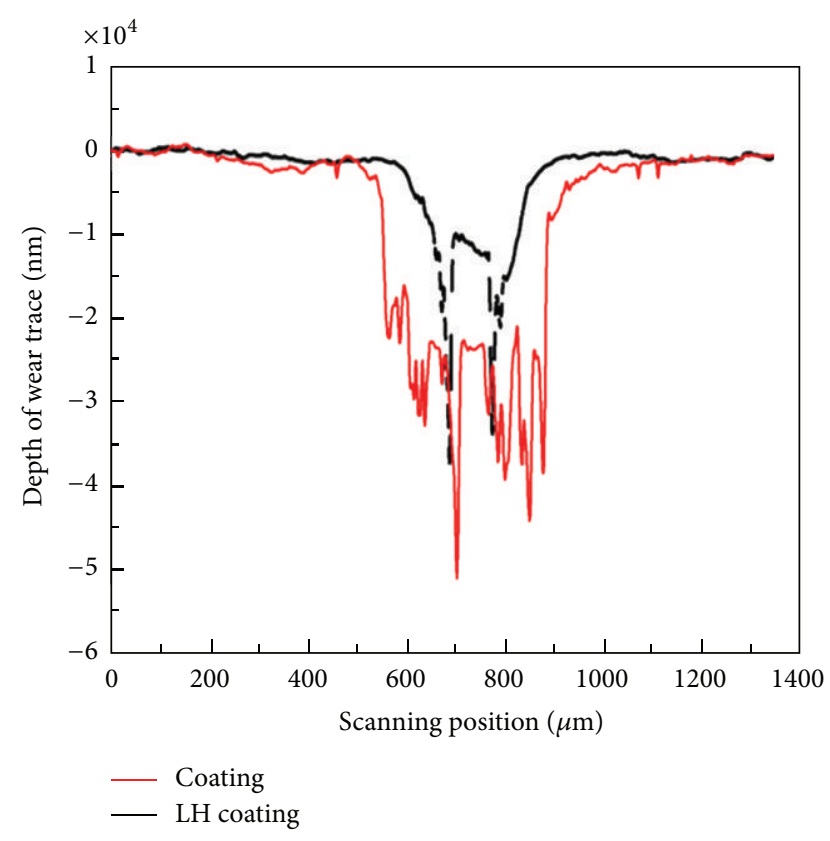

FIGURE 6: Wear depth profiles of coating and LH coating at room temperature.

temperature dependence of wear resistance of In718, coating, and $\mathrm{LH}$ coating. As seen in Figures $4 \sim 6$, the wear resistance was improved by HVOF coating and followed by LH coating, since the surface hardness increased by coating, followed by $\mathrm{LH}$ coating in Section 3.2. The temperature dependence of wear resistance of the coating was better than that of In718 which showed a narrower wear trace and shallower wear depth at $25^{\circ} \mathrm{C}$ and $450^{\circ} \mathrm{C}$ in Figures 4 and 5. With surface temperature increase from $25^{\circ} \mathrm{C}$ to $450^{\circ} \mathrm{C}$ the wear width and depth increased at In718 and the coating. This showed that the wear resistances decreased with surface temperature increase at In718 and the coating because thermal effect

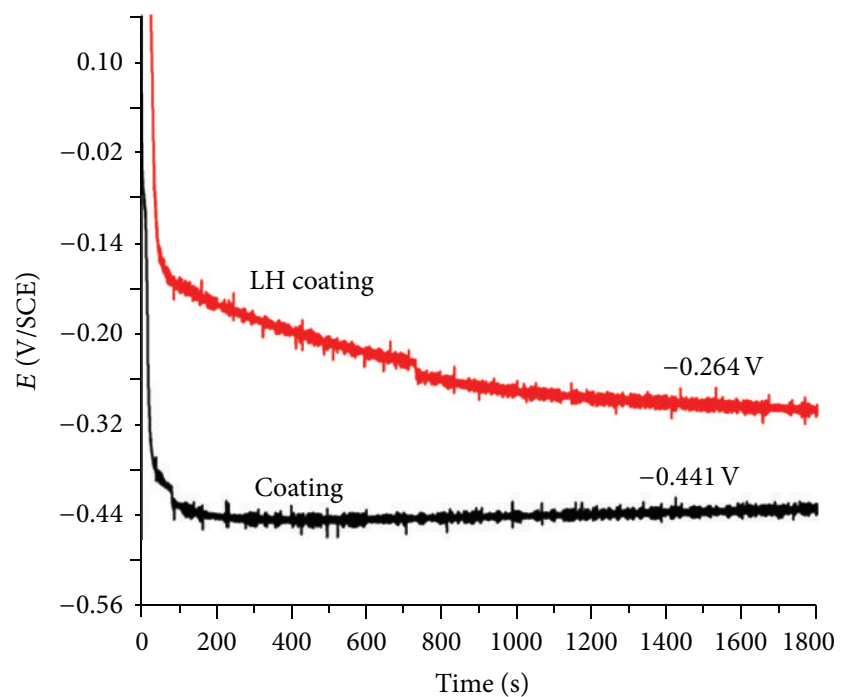

FIGURE 7: Corrosion potential and time of coating and LH coating in sea water $(3.5 \% \mathrm{NaCl})$.

softens the surface and there was wear debris of metal oxides and free carbon decomposed by thermal effect functioning as solid and liquid lubricants. The lubricating effect was higher at higher temperature. As seen in Figure 6, the wear resistance of the coating increased by laser heating, showing a decrease of wear depth from $5000 \mathrm{~nm}$ to $2000 \mathrm{~nm}$ due to the increase of surface hardness by laser heating as discussed in Section 3.2.

3.4. Improvement of Corrosion Resistance by Coating and by LH Coating. Corrosion behaviors of In718, HVOF coating, and $\mathrm{LH}$ coating in $3.5 \% \mathrm{NaCl}$ solution (sea water) were investigated. As previously reported by S. Y. Park and C. G. Park [4], corrosion resistance of In718 surface was improved by $\mathrm{HVOF}$ coating of WC-metal powder in $3.5 \% \mathrm{NaCl}$ solution and $1 \mathrm{M} \mathrm{HCl}$ acid, but it decreased in $1 \mathrm{M} \mathrm{NaOH}$ base solution. 


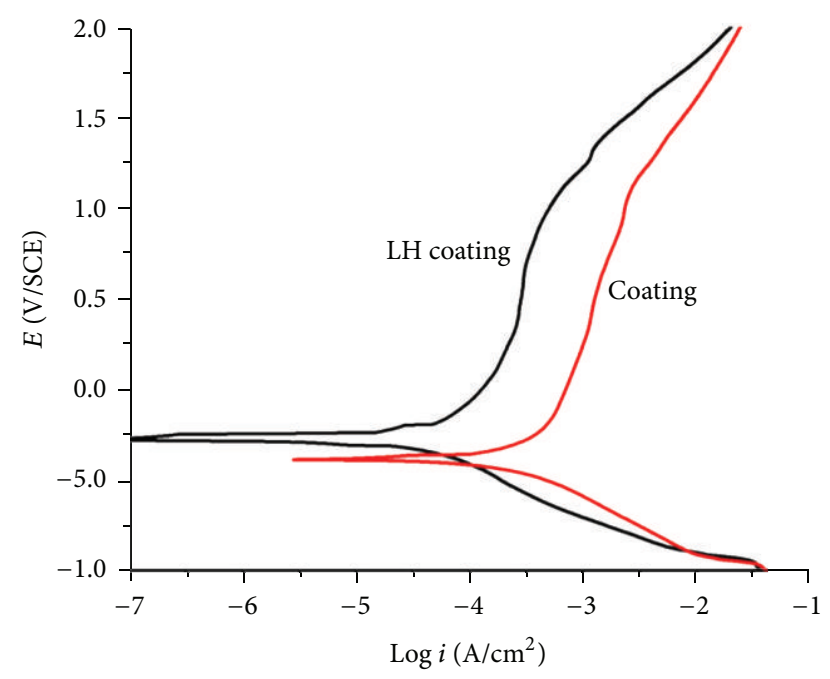

FIGURE 8: Potentiodynamic polarization of coating and LH coating in sea water $(3.5 \% \mathrm{NaCl})$.

In718 with $100 \%$ metals was more corrosive (chemically active) than the coating (WC-metal) with more than $50 \%$ inactive cermet of WC. As shown in Figures 7 and 8, the corrosion resistance of coating in $3.5 \% \mathrm{NaCl}$ solution was improved by laser heating. As seen in Figure 7, corrosion potential decreased and then stayed steady with corrosion time; this suggested the corrosion films on both coating and LH coating were not passive films and did not protect the inner materials of the coating.

The LH coating with lower porosity (dense coating) had higher corrosion potential than the coating. Therefore the LH coating had more corrosion resistance than the coating. As seen in Figure 8, LH coating had a smaller corrosion current density and higher breakdown potential (pitting potential or corroded film breakdown potential), showing LH coating was a better corrosion resistance. The corrosion current density increased rapidly with a small increase of applied potential and there was no significant passive region for both the coating and LH coating. This showed that no protective corrosion films were formed at both coating and LH coating. The very active chlorine ions strongly reacted with the surface atoms but did not form protective passive films on the surface [11].

\section{Conclusions}

The following conclusions were derived from the investigation of improvement of surface properties of In718 by HVOF coating of WC-metal powder and by laser heating of the coating.

(1) Metal carbides and WC decomposed during the $\mathrm{HVOF}$ coating, forming less hard $\mathrm{W}_{2} \mathrm{C}$ phase and free carbon.

(2) Porous coating was formed by HVOF coating, but it was compacted from $2.5 \pm 0.5 \%$ to $0.35 \pm 0.05 \%$ (to $14 \%)$ by the laser heating.
(3) The surface hardness of In718 surface improved from $400 \pm 10 \mathrm{Hv}$ to $980 \pm 100 \mathrm{Hv}$ by the coating; it was further increased to $1430 \pm 90 \mathrm{Hv}$ by laser heating.

(4) Friction coefficient of In718 reduced from $0.45 \pm 0.08$ to $0.32 \pm 0.02$ by the coating and to $0.20 \pm 0.03$ by the laser heating.

(5) Wear resistance of In718 surface was improved by the coating and further improved by LH coating. And these resistances were decreased with increasing surface temperature in the temperature range from $25^{\circ} \mathrm{C}$ to $450^{\circ} \mathrm{C}$.

(6) Corrosion resistance improved by HVOF coating, followed by LH coating.

(7) For the improvement of surface properties and durability of materials, HVOF coating of WC-metal powder on the surface and laser heat-treated coating were strongly recommended.

\section{Conflict of Interests}

The authors declare that there is no conflict of interests regarding the publication of this paper.

\section{Acknowledgments}

This research was financially supported by R\&D fund of the University of Ulsan, Korea. The authors would like to express their sincere thanks for the support. They also would like to thank Dr. Gun Hwan Lee who contributed to investigating of the surface properties of the substrates and the coatings.

\section{References}

[1] J. R. Davis, Handbook of Thermal Spray Technology, ASM International, 2004.

[2] B. D. Sartwell, K. O. Legg, J. Schell, J. Sauer, and P. Natishan, "Validation of HVOF WC/Co thermal spray coatings as a replacement for hard chrome plating on aircraft landing gear," DTIC Document, 2004.

[3] T. Y. Cho, H. G. Chun, Y. K. Joo, and J. H. Yoon, "A study on HVOF coating of WC-metal powder on super alloy In718 of magnetic bearing shaft material of turbo-blower," International Journal of Precision Engineering and Manufacturing, vol. 15, no. 7, pp. 1479-1484, 2014.

[4] S. Y. Park and C. G. Park, "Wear properties of WC-Co nanoparticle coatings fabricated by detonation gun spraying," Journal of the Korean Institute of Metals and Materials, vol. 42, p. 582, 2004.

[5] T. Y. Cho, J. H. Yoon, K. S. Kim et al., "A study on HVOF coatings of micron and nano WC-Co powders," Surface and Coatings Technology, vol. 202, no. 22-23, pp. 5556-5559, 2008.

[6] W. Fang, T. Y. Cho, J. H. Yoon et al., "Processing optimization, surface properties and wear behavior of HVOF spraying WCCrC-Ni coating," Journal of Materials Processing Technology, vol. 209, no. 7, pp. 3561-3567, 2009.

[7] U. T. Kim, D. W. Park, J. S. Kim, Y. S. Kwon, H. S. Kwon, and B. R. Baek, "Spark plasma sintering behavior of binderless WC powders," Journal of Korean Powder Metallurgy Institute, vol. 10, no. 3, pp. 176-180, 2003. 
[8] S.-H. Zhang, T.-Y. Cho, J.-H. Yoon et al., "Characterization of microstructure and surface properties of hybrid coatings of WC-CoCr prepared by laser heat treatment and high velocity oxygen fuel spraying," Materials Characterization, vol. 59, no. 10, pp. 1412-1418, 2008.

[9] P. Chivavibaul, M. Watanabe, S. Kuroda, and K. Shinoda, "Effects of carbide size and Co content on the microstructure and mechanical properties of HVOF-sprayed WC-Co coating," Surface \& Coating Technology, vol. 202, p. 509, 2004.

[10] H. H. Ulig and R. W. Revie, Corrosion and Corrosion Control, 1985.

[11] T. Y. Cho, J. H. Yoon, K. S. Kim et al., "Friction behavior of HVOF thermal spray coating of micron size WC-Co powder," Advanced Materials Research, vol. 26, pp. 1325-1328, 2007. 

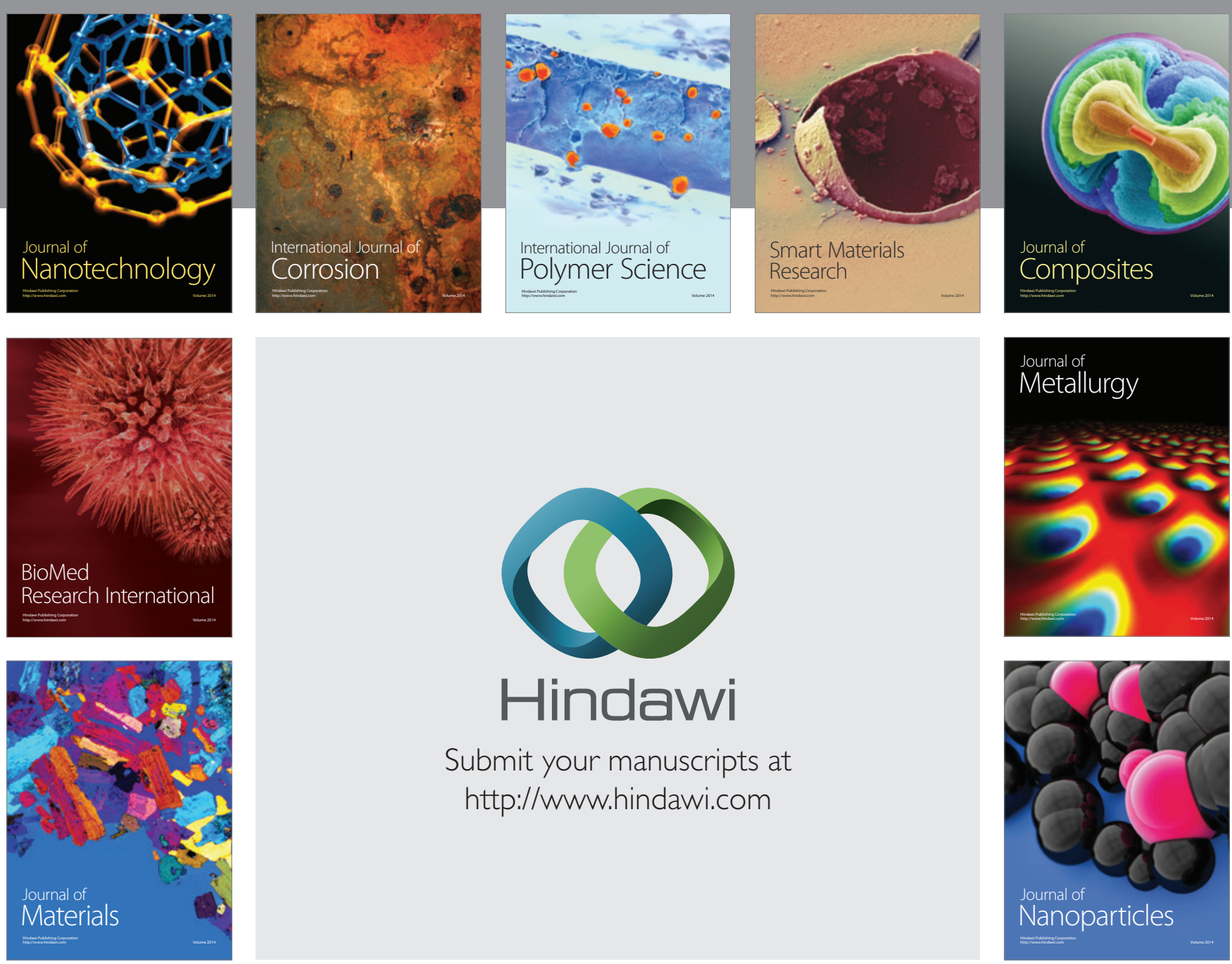

Submit your manuscripts at http://www.hindawi.com
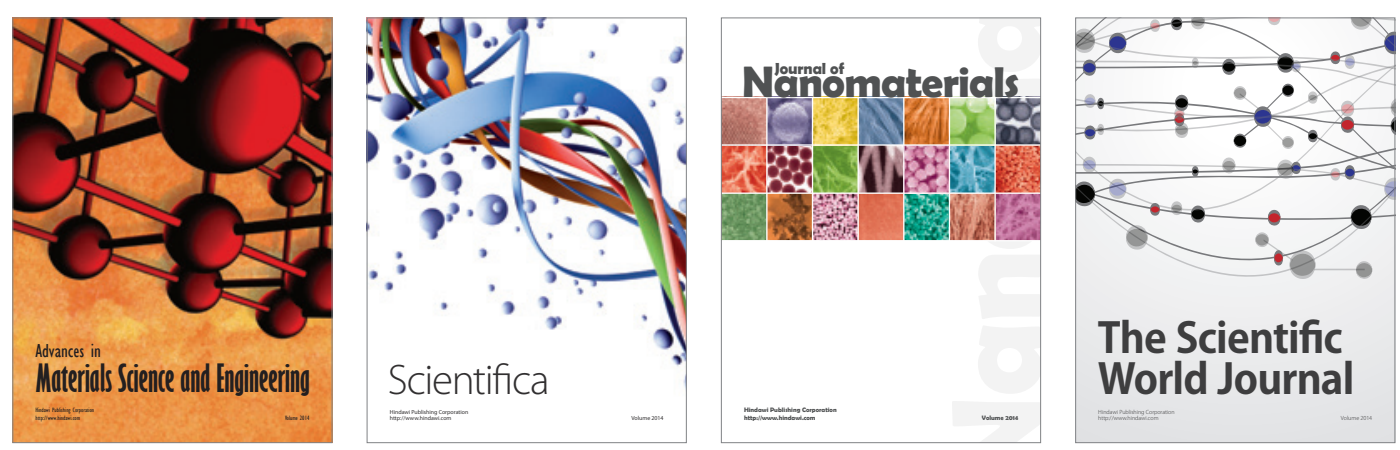

\section{The Scientific World Journal}
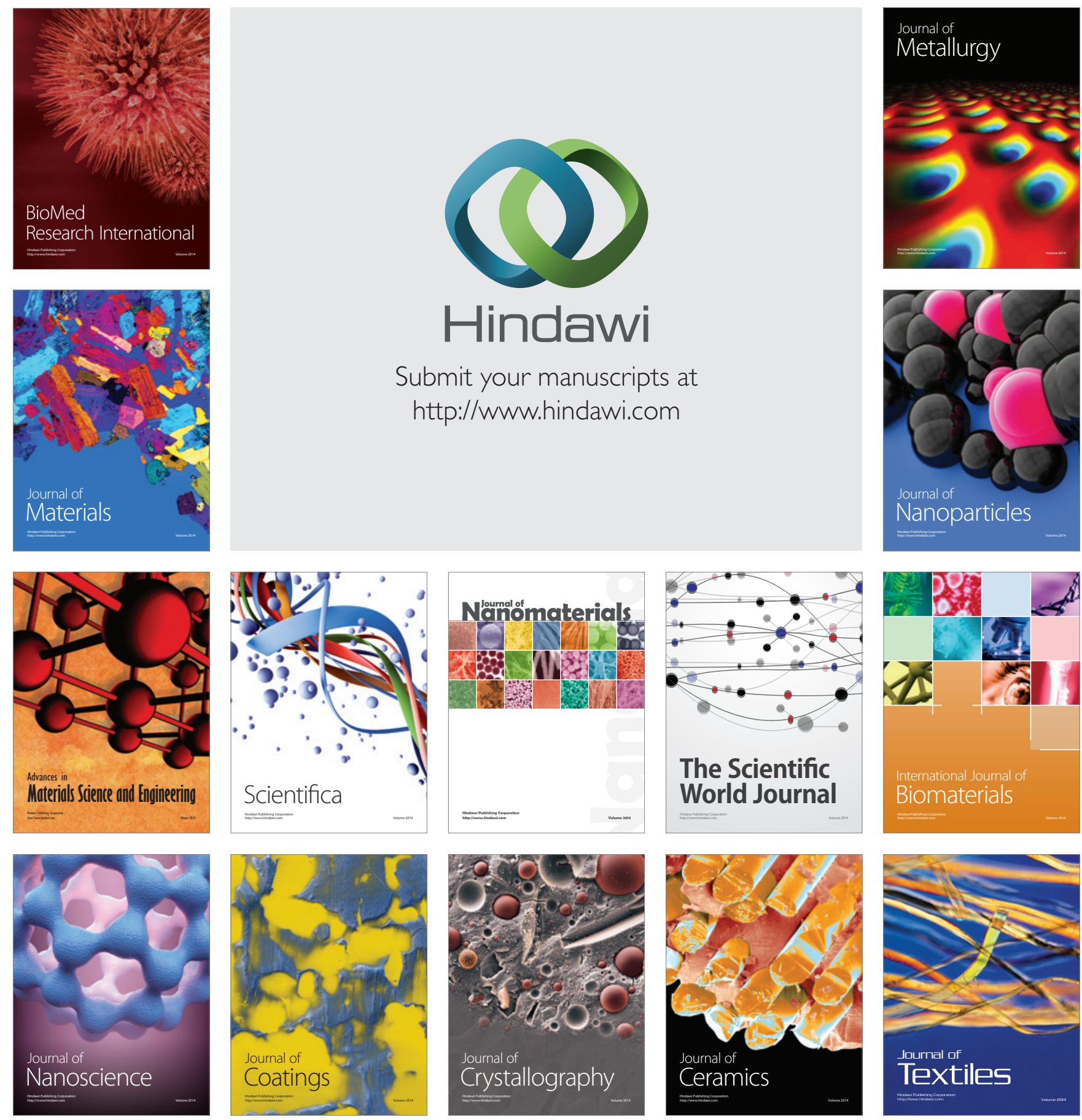